Universidad de Lima

Facultad de Ciencias Empresariales y Económicas

Carrera de Administración

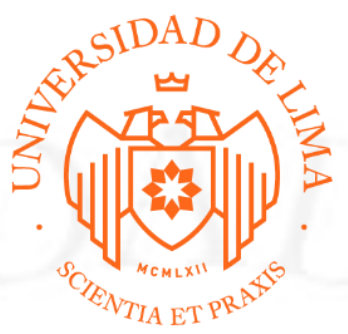

\title{
SUSTENTACIÓN DE CASO: PROPUESTA DE UN PLAN ESTRATÉGICO DEL INGRESO AL MERCADO PERUANO DE UNA EMPRESA DEL SECTOR FAST FASHION
}

Trabajo de suficiencia profesional para optar el Título Profesional de Licenciado en Administración

\section{Lisbeth Brenda Yrribarren Salcedo}

Código 20102003

$$
\text { Lima - Perú }
$$

Noviembre del 2018 


\section{SUSTENTACIÓN DE CASO: PROPUESTA DE UN PLAN ESTRATÉGICO DEL INGRESO AL MERCADO PERUANO DE UNA EMPRESA DEL SECTOR FAST FASHION}




\section{TABLA DE CONTENIDO}

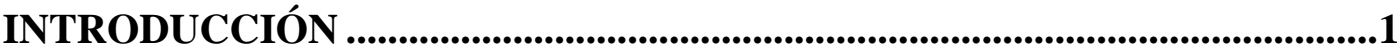

CAPÍTULO I: DIAGNOSTICO ESTRATEGICO ............................................2

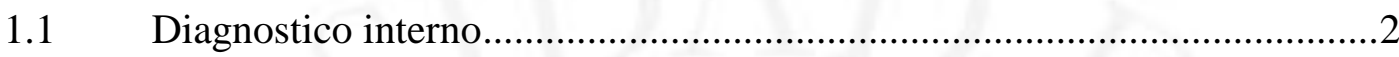

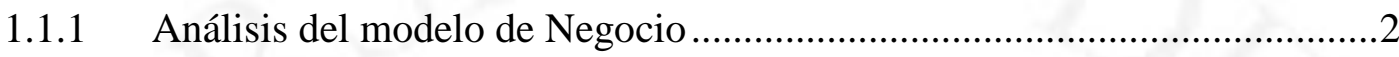

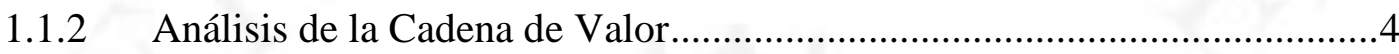

1.1.3 Definición y sustentación de las ventajas competitivas de la empresa y por

UEN

1.1.4 Determinación y sustentación las Fortalezas y Debilidades de la empresa y por

UEN

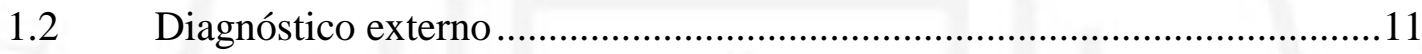

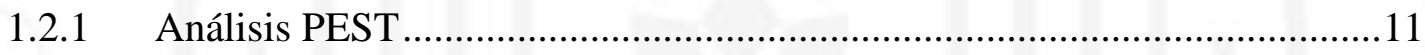

1.2.2 Analisis de las fuerzas competitivas del sector industrial .........................13

1.2.3 Determinación y Sustentación de las Oportunidades y Amenazas...............15

CAPÍTULO II: FORMULACIÓN DE LA ESTRATEGIA ...................................18

2.1 Desarrollo y sustentación de la Matriz EFI ..............................................18

2.2 Desarrollo y sustentación de la Matriz EFE ..............................................19

2.3 Matriz de las Estrategias Genéricas .....................................................20

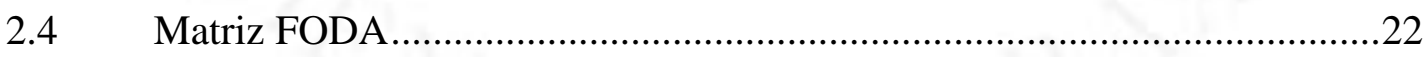

2.5 Definición y Sustentación de la Visión, Misión y Políticas ........................23

2.6 Definición de los Objetivos Estratégicos de la Empresa ............................23

2.7 Redefinición de las UEN (Unidad Estratégica de Negocios) o creación de

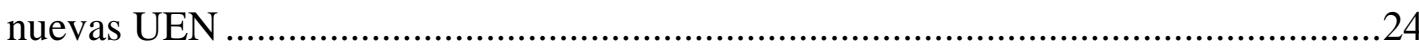


2.8 Propuesta y sustentación de Estrategias en el ambiente Global, Corporativas,

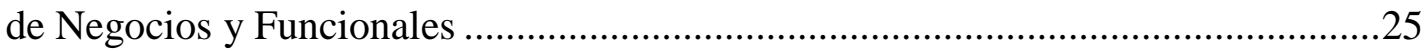

CAPÍTULO III: IMPLEMENTACIÓN ESTRATÉGICA.....................................29

3.1 Evaluación del rediseño o no rediseño de la estructura organizacional de la empresa (Sustento)

3.2 Propuesta de cambios para mejorar la implementación de estrategias en la empresa

CAPÍTULO IV: CONTROL ESTRATÉGICO.

4.1 Diseño de un Mapa Estratégico de Control para la empresa .32

4.2 Desarrollo de un Cuadro de Mando Integral con un mínimo de 10 índices de gestión (Sustento) (Cuatro Perspectivas) ...................................................................33

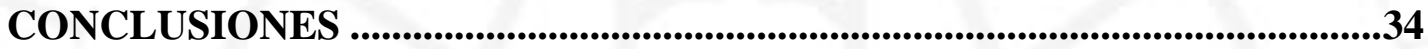

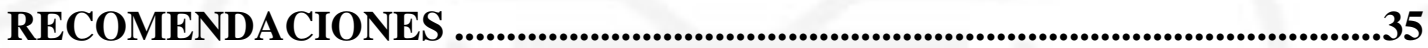

REFERENCIAS BIBLIOGRÁFICAS .......................................................................36 


\section{ÍNDICE DE TABLAS}

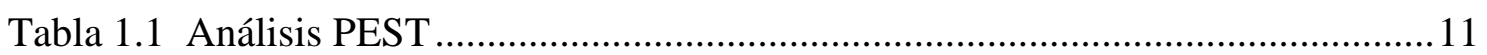

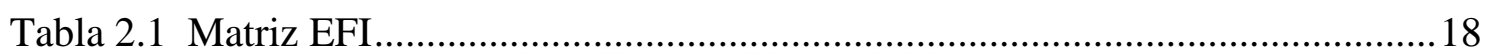

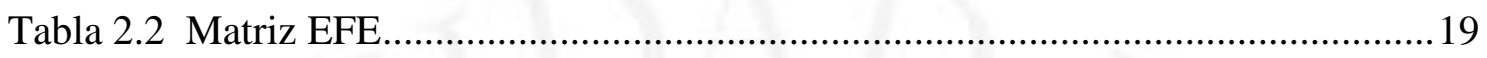

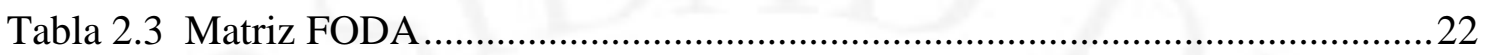

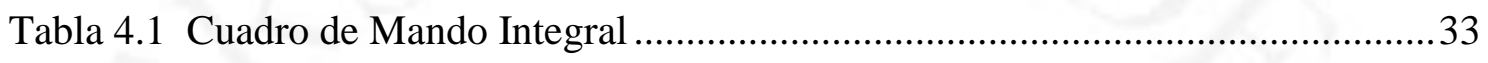




\section{ÍNDICE DE FIGURAS}

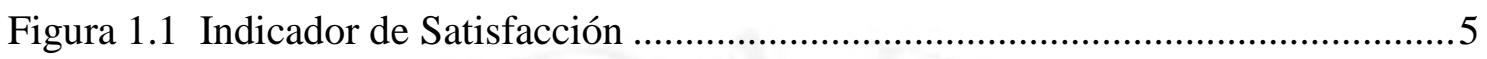

Figura 2.1 Matriz de las Estrategias Genéricas.......................................................20

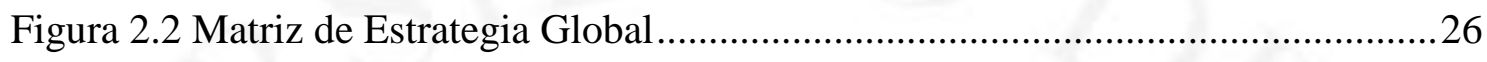

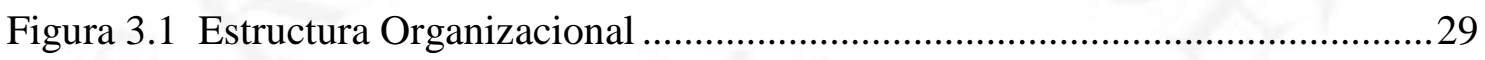

Figura 4.1 Mapa Estratégico de Control ................................................................ 32 


\section{INTRODUCCIÓN}

El presente trabajo de suficiencia profesional tiene como objetivo estructurar un análisis empresarial y plan estratégico para el Grupo japonés Fast Retailing, dueño de UNIQLO, GU, Theory, Comptoir des Contonniers, Princesse tam.tam y J Brand; con la finalidad de asesorar su ingreso al Perú en el año 2019.

El análisis iniciará con el diagnóstico interno con la finalidad de establecer sus capacidades, recursos y áreas claves de la compañía. Luego se realizará un diagnóstico externo dirigido al mercado peruano para determinar las oportunidades y amenazas del entorno.

La formulación de la estrategia se enfocará en analizar a UNIQLO, la marca más representativa del grupo que aporta más del $80 \%$ de sus ingresos, ya que esta sería la elegida para ingresar al país. Por último, se propondrá cambios parar su mejor implementación y un cuadro de control con indicadores de gestión para asegurar el seguimiento.

Es importante mencionar que el presente plan tendrá mayor énfasis en el área de Marketing y Logística, que fueron seleccionadas para el proceso de titulación. 


\section{CAPÍTULO I: DIAGNÓSTICO ESTRATÉGICO}

\subsection{Diagnóstico interno}

\subsubsection{Análisis del modelo de Negocio}

Según Alexander Osterwalder e Yves Pigneur (2010):

"The business model can best be described through nine basic building blocks that show the logic of how a company intends to make money. The nine blocks cover the four main areas of a business: customers, offer, infrastructure, and financial viability." [El modelo de negocio se puede describir mejor a través de nueve componentes básicos que muestran la lógica de cómo una empresa intenta ganar dinero. Los nueve bloques cubren las cuatro áreas principales de un negocio: clientes, oferta, infraestructura y viabilidad financiera.] (p. 21)

A continuación, se analizará el modelo de negocios de Fast Retailing.

Propuesta de valor: Ofrecer ropa casual y básica de buena calidad e innovadoras a un precio razonable dirigida a todos, sin importar la edad, raza, entre otros. Brindando una experiencia de compra diferenciada basada en el servicio al cliente.

Segmento de Clientes: Se dirige a un mercado masivo, hombres y mujeres de 20-60 años en busca de prendas minimalistas de calidad a buen precio.

\section{Canales:}

- Tiendas: cuentan con locales en ubicaciones estratégicas.

- Venta online mediante su página web y App.

- Publicidad en medios tradicionales periódicos, televisión y medios modernos. Como la web, redes sociales y Blog.

Relación con el cliente: El enfoque principal de Fast Retailing es la satisfacción de sus clientes; recogen comentarios de sus usuarios para desarrollar productos de acuerdo a sus preferencias. Asimismo, tienen un servicio de calidad al contar con personal capacitado $\mathrm{y}$ atento. 
Fuente de ingreso: El ingreso de ventas de locales y tienda virtual mediante efectivo y tarjetas de crédito.

\section{Recurso Clave}

- El recurso humano capacitado y alineado a los principios de la empresa.

- Locales de venta ubicados estratégicamente en mercados de alta demanda.

- Infraestructura web orientada a la venta online y a mantener una relación más cercana con sus clientes.

- Recurso intangible: sus marcas son reconocidas en los mercados en los que operan. UNIQLO es la tercera compañía más admirada en Japón. (Takeuchi, 2012)

\section{Actividades Claves}

- Diseño de materiales innovadores.

- La compra de gran volumen de materia prima de calidad para obtener una estructura de costos eficiente.

- Control total de todo el proceso de fabricación desde el desarrollo de sus diseños.

- Capacitación de todo su personal con enfoque hacia el cliente y servicio de calidad. Además del desarrollo de un centro de formación de futuros líderes.

- Publicidad de sus promociones y características diferenciadoras de sus prendas de vestir.

\section{Socios Clave}

- Proveedores de materia prima.

- Fábricas seleccionadas que manufacturan sus productos.

- Diseñadores con los que lanzan colecciones, Línea J de Gil Sander.

- Embajadores de marca reconocidos internacionalmente.

\section{Estructura de Costos}

- Logístico e inventarios

- Infraestructura de los locales

- Producción y Materia prima

- Personal y capacitaciones 
- $\quad$ Marketing

\subsubsection{Análisis de la Cadena de Valor}

Según Hill y Jones (2010), la cadena de valor describe el conjunto de las actividades principales y de apoyo de una organización que generan valor al producto. (p.81)

\section{Actividades primarias}

Investigación + Desarrollo: Fast Retailing inicia con la planificación de sus productos, que va desde la selección de materia prima, el desarrollo de materiales y termina con el diseño de las muestras. Es importante destacar que cuentan con centros de investigación que buscan lanzar textiles tecnológicos que satisfagan las necesidades de sus clientes.

Fabricación: Fast Retailing controla todo el proceso de elaboración de sus prendas. Asimismo, cuenta con relaciones estrechas con un número limitado de fábricas, las cuales visitan semanalmente para supervisar los procesos. Es importante mencionar, que la planificación de su producción se hace un año antes y solo se enfocan en producir algunos estilos básicos. (Takeuchi, 2012)

Logística: La compañía tiene alianzas estratégicas con operadores que se encarguen de su distribución. Asimismo, la empresa negocia directamente con los fabricantes para realizar compras a volumen y asegurar insumos de buena calidad a excelente precio. Este proceso es un punto estratégico para su negocio ya que lo trasladan al precio final de sus productos. (Takeuchi, 2012)

Marketing y ventas: Fast Retailing tiene muy bien definidas sus marcas, ejemplo de esto es UNIQLO, empresa con una visión clara que trasmite constantemente su promesa de marca en toda la experiencia de compra de sus consumidores.

El marketing integra todo contacto con sus clientes que va desde las ubicaciones de los locales, así como su diseño y distribución. Asimismo, utilizan los medios tradicionales y digitales para publicar sus campañas publicitarias dando a conocer sus productos más innovadores.

Adicional a lo antes mencionado UNIQLO viene trabajando con embajadores de la marca como deportistas de fama internacional como Roger Federer, con el objetivo de hacer la marca más conocida. Por último, tiene colaboraciones con diseñadores conocidos que ha ayudado a llegar a nuevos segmentos de mercado. 
Con respecto a sus ventas, la empresa cuenta con un equipo capacitado y empoderado en sus tiendas. De igual manera, ha desarrolla un canal de venta online que actualmente tiene bastante importancia en la compañía.

Servicio post venta: la empresa mantiene una comunicación abierta con sus clientes para cumplir con sus expectativas. Los clientes reciben una encuesta por email después de la compra de algún producto, generando un indicador importante de satisfacción de sus consumidores. Adicionalmente, cuenta con centros de atención al cliente eficientes que dan una respuesta rápida a los clientes realizan un reclamo.

Figura 1.1

Indicador de Satisfacción

Results of the customer satisfactoin survey (UNIQLO)

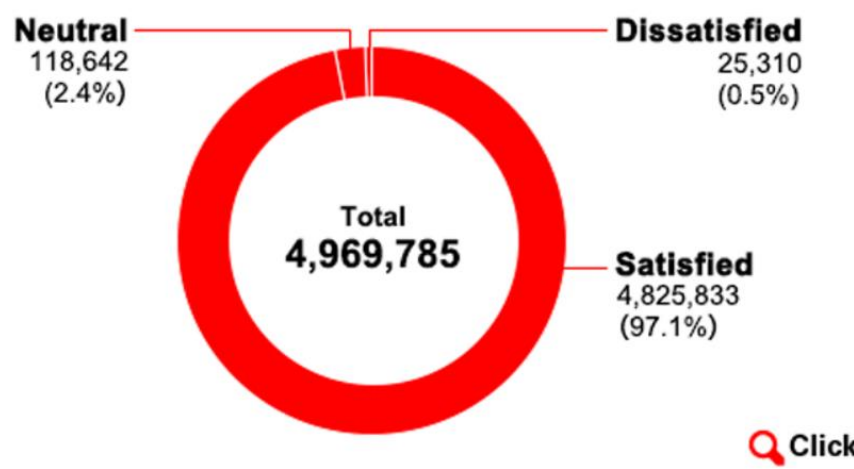

Fuente: Fast retailing (2018)

Es importante mencionar, que UNIQLO fue el primer minorista de ropa en Japón en tener una política de devolución y cambio hasta tres meses después de la compra.

\section{Actividades de soporte}

Gestión de Recursos Humanos: La empresa se preocupa bastante por la capacitación de sus empleados. Un claro ejemplo de esto, es la creación de un centro de formación de futuros líderes con la finalidad de preparar a 200 ejecutivos que asuman puestos directivos en el futuro. Asimismo, los colaboradores de las tiendas tienen una línea de carrera motivadora y atractiva, cuyo objetivo final es convertirse en dueños de una franquicia. (Takeuchi, 2012)

Desarrollo de la Tecnología: La empresa se enfoca en la innovación, uno de lanzamientos más exitosos es HEATTECH desarrollada con Toray Industries. 
Infraestructura de la empresa: La empresa cuenta con áreas de apoyo de planeación, finanzas y contabilidad. El buen manejo de su capital económico ha permitido la expansión de la marca

Sistemas de información: cuentan con la estructura de software y hardware fundamentales para el desempeño de la compañía.

\subsubsection{Definición y sustentación de las ventajas competitivas de la empresa y por UEN}

\section{UNIQLO Japón}

Eficiencia Superior: La empresa es bastante productiva con sus recursos. Las principales actividades de su cadena de suministro se trabajan con grandes volúmenes para conseguir mejores costos. Esto se puede apreciar en las compras masivas a productores para negociar los precios más bajos. Otro punto a resaltar, es el portafolio eficiente que manejan en sus tiendas al restringir su gama de productos por 3,3 metros cuadrados. (Takeuchi, H,2012, p.8)

Calidad Superior: UNIQLO controla la calidad de toda su cadena de valor. Buscan en todo el mundo las mejores materias primas para fabricar sus prendas. También aseguran la calidad mediante alianzas estratégicas con un número limitado de fábricas, que son visitadas semanales por supervisores con más de 30 años de experiencia.

Superior capacidad de satisfacción al cliente: UNIQLO recoge las opiniones de los clientes para desarrollar productos de acuerdo a sus necesidades. También se caracterizan por una atención amable en sus puntos de ventas.

Innovación Superior: Se enfocan en desarrollar productos que mejoren la vida de las personas a través de nuevos textiles que satisfagan las necesidades de sus clientes. Cuenta con centros de investigación y alianzas estratégicas para lanzar productos diferentes. Asimismo, buscan el avance de la experiencia de compra de sus usuarios mediante complementos a su venta online como UNIQLO IQ un asistente de compras virtual. (Perú Retail, 2018, párr.9) 


\section{UNIQLO Internacional}

Esta unidad de negocio tiene las mismas ventajas competitivas que UNIQLO Japón al ser una ampliación de esta para otros mercados.

\section{Marcas Globales}

Calidad superior: las marcas Theory, CDC y PTT desarrollan diseños modernos y usan materiales superiores para obtener productos de calidad; el segmento al que se dirigen es más reducido.

\section{GU}

Eficiencia Superior: GU es una marca que tiene como prioridad ofrecer precios bajos a través del modelo SPA. Los productos que comercializan son de menor calidad.

\section{Fast Retailing}

Después de analizar la ventaja competitiva por cada UEN, podemos determinar que el grupo japonés ha desarrollado los cuatro bloques de la ventaja competitiva, dándole una posición sólida en el sector que le ha permitido crecer de forma excepcional.

Es importante mencionar que las UEN trabajadas se obtuvieron de la memoria anual de Fast retailing del 2017, lo que explica la variación de la UEN GU con la expuesta en el caso.

\subsubsection{Determinación y sustentación las Fortalezas y Debilidades de la empresa y por UEN}

El análisis interno debe culminar con una evaluación clara de los recursos de la organización y su capacidad para realizar diferentes actividades funcionales. (Robbins, Stephen P. y Coulter, 2014, p.184)

\section{Fast Retailing}

Fortaleza

- Cuenta con un líder innovador con visión clara como Yanai Tadashi. Escribió 23 principios de gestión que son el alma de la compañía.

- La compañía cuenta con un enfoque social. Su objetivo es crecer en armonía con la sociedad y contribuir a su mejora. 
- Notoriedad del grupo japonés a nivel internacional debido a su gran éxito en el mercado asiático y propuesta innovadora.

Debilidades

- No cuentan con los directivos preparados para conducir la implementación y desarrollo en nuevos países. La rápida expansión geográfica puso en evidencia la falta de líderes alineados a la cultura corporativa.

\section{UNIQLO Japón y UNIQLO Internacional}

Se empezará definiendo las fortalezas y debilidades que comparten estas dos UEN.

Fortalezas:

- Cultura corporativa sólida, orientada a la satisfacción del cliente y alineada a los objetivos de la compañía.

- Cadena de valor controlada que les permite ofrecer prendas de vestir esenciales de muy buena calidad y perdurables en el tiempo a precios razonables.

- Cuenta con centros de investigación para desarrollar innovaciones tecnológicas textiles únicas. Algunos de sus lanzamientos más recordados son: Airism, HeatTech y Ultra Light Down.

- Ofrecer prendas de vestir que brinden soluciones innovadoras a las necesidades del día a día de las personas a precios razonables. Los líderes del Fast Fashion venden moda mientras que UNIQLO vende tecnología.

- Se dirige a un segmento bastante amplio, dándole mayor potencial de crecimiento a diferencia de sus competidores. El lema inicial de Uniqlo era Hecho para todos.

- Colaboraciones con diseñadores importantes, la colección más célebre fue $+\mathrm{J}$ del diseñador alemán Jil Sander. (Takeuchi, 2012)

- La calidad de atención y servicio post venta. Mantienen una comunicación permanente con sus clientes para asegurar la satisfacción de la compra.

- Cuentan con un sólido canal de e-commerce, debido a la amplia experiencia que tienen en este ámbito.

Debilidades 
- Su logística es bastante lenta comparada con Inditex, el líder de la industria. Zara tarda dos semanas desde el diseño hasta la entrega en tienda. (Bloomberg,2017, párr.2)

- No diseña ropa en base a las modas pasajeras. Existe una población considerable que busca vestirse con las últimas tendencias que no encuentra atractiva la propuesta de UNIQLO.

\section{UNIQLO Japón}

Fortaleza

- Es la empresa líder del sector textil. Cuenta con bastante experiencia en el mercado japonés, conoce a sus consumidores y sabe que estrategias funcionan. Asimismo, cuentan con una gran red de tiendas distribuidas en todo el país.

- UNIQLO es una de las marcas más posicionadas en Japón. Muchos jóvenes profesionales aspiran trabajar en la compañía. Además, cuenta con gran porcentaje de clientes fidelizados.

Debilidad

- El crecimiento de la marca es más lento que en otras UEN, ya que se trata de una zona consolidada con muchos años operación.

\section{UNIQLO Internacional}

Fortaleza

- La marca está en una etapa temprana de desarrollo. Tiene mucho potencial para crecer y consolidarse como líder en los nuevos mercados.

Debilidades

- Poca experiencia operando en el mercado occidental en donde Inditex y H\&M están bastante desarrollados.

- Sus productos están dirigidos a satisfacer las necesidades del mercado asiático. El estilo minimalista que propone es muy aceptado en Japón, sin embargo, este no tiene la misma acogida en otros países que están acostumbrado a la ropa de moda. 
- Desconocimiento de la marca en Sudamérica, la mayoría de personas no conocen la tienda, ni tienen clara su propuesta diferenciada.

\section{Marcas Globales}

\section{Fortalezas}

- Sus diseños son modernos y tienen mucho estilo.

- La calidad de sus insumos es muy buena, lo que conlleva a tener productos finales de beneficios diferenciados.

Debilidades:

- Los segmentos al cual se dirigen son más reducidos.

- Baja expansión y reconocimiento a nivel mundial.

\section{GU}

Fortaleza:

- Emplean el modelo SPA, que les permite tener una baja estructura de costos

\section{Debilidades}

- Los productos son de menor calidad que las otras marcas, ya que su prioridad es tener precios bajos.

- Marca con poca expansión internacional. 


\subsection{Diagnóstico externo}

\subsubsection{Análisis PEST}

Según Hitt, Ireland y Hoskisson (2015), las organizaciones deben prestar atención a los factores del macroentorno para aprovecharlos o disminuir un impacto negativo.

Tabla 1.1

Análisis PEST

\begin{tabular}{|c|c|c|}
\hline Factores & Escenario & Evolución Futura \\
\hline $\begin{array}{l}\text { Político- } \\
\text { Legal }\end{array}$ & $\begin{array}{l}\text { Crisis política debido a los enfrentamientos } \\
\text { entre el poder ejecutivo y legislativo que a } \\
\text { frenado los proyectos públicos y privados. } \\
\text { Además se han reportado fuertes casos de } \\
\text { corrupción. }\end{array}$ & $\begin{array}{l}12 \text { meses- Amenaza } \\
\text { 1-3 años - Oportunidad } \\
\text { 3-5 años - Oportunidad }\end{array}$ \\
\hline $\begin{array}{l}\text { Político- } \\
\text { Legal }\end{array}$ & $\begin{array}{l}\text { Las legislaciones laborales son rígidas y } \\
\text { presentan poca flexibilidad en la } \\
\text { desvinculación de los trabajadores. Según } \\
\text { Rossini (2014), Gerente General del BCR "La } \\
\text { tendencia de la legislación laboral peruana es } \\
\text { querer proteger al trabajador y en realidad está } \\
\text { afectándolo y lanzándolo a la informalidad" } \\
\text { (párr.2). }\end{array}$ & $\begin{array}{l}12 \text { meses- Amenaza } \\
\text { 1-3 años - Amenaza } \\
\text { 3-5 años - Oportunidad }\end{array}$ \\
\hline $\begin{array}{l}\text { Político- } \\
\text { Legal }\end{array}$ & $\begin{array}{l}\text { "La política fiscal del Perú es una las mejores } \\
\text { de América Latina."(Vega Polanco, 2017, } \\
\text { párr.1) }\end{array}$ & $\begin{array}{l}12 \text { meses- Oportunidad } \\
\text { 1-3 años - Oportunidad } \\
\text { 3-5 años - Oportunidad }\end{array}$ \\
\hline Económico & $\begin{array}{l}\text { El Perú ha gozado de un crecimiento } \\
\text { económico sostenible como resultado de los } \\
\text { esfuerzos del gobierno nacional por promover } \\
\text { la integración comercial con otros países. }\end{array}$ & $\begin{array}{l}12 \text { meses- Oportunidad } \\
\text { 1-3 años - Oportunidad } \\
\text { 3-5 años - Oportunidad }\end{array}$ \\
\hline Económico & $\begin{array}{l}\text { Se estima cerrar el año con un crecimiento del } \\
9 \% \text { en el sector Retail. (CCL,2018, párr.1). }\end{array}$ & $\begin{array}{l}12 \text { meses- Oportunidad } \\
\text { 1-3 años - Oportunidad } \\
\text { 3-5 años - Oportunidad }\end{array}$ \\
\hline Económico & $\begin{array}{l}\text { El sector minorista textil peruano cuenta con } \\
\text { competidores como H\&M, Inditex y Forever } \\
21 \text { y también con tiendas departamentales que } \\
\text { estan reaccionando a su entorno, mediante la } \\
\text { innovación y el desarrollo de sus marcas } \\
\text { propias. }\end{array}$ & $\begin{array}{l}12 \text { meses- Amenaza } \\
\text { 1-3 años - Amenaza } \\
\text { 3-5 años - Amenaza }\end{array}$ \\
\hline
\end{tabular}

(continúa) 


\begin{tabular}{|c|c|c|}
\hline $\begin{array}{l}\text { Socio } \\
\text { cultural } \\
\text { Ambiental }\end{array}$ & $\begin{array}{l}\text { El país cuenta con una población } 31 \text { millones, } \\
\text { de cuales el } 60 \% \text { corresponde a los sectores } \\
\text { socioeconómicos } \mathrm{C} \text { y D. "En las ciudades con } \\
\text { más de } 200 \text { mil habitantes, el } 3.7 \% \text { pertenece } \\
\text { al segmento A; el } 16.2 \% \text {, al B, el } 35.2 \% \text {, al C, } \\
\text { el } 32.3 \% \text {, al D y } 12.6 \% \text {, al E." (Ipsos Perú, } \\
2013 \text {, párr.5 ) }\end{array}$ & $\begin{array}{l}12 \text { meses- Amenaza } \\
\text { 1-3 años - Amenaza } \\
\text { 3-5 años - Oportunidad }\end{array}$ \\
\hline $\begin{array}{l}\text { Socio } \\
\text { cultural } \\
\text { Ambiental }\end{array}$ & $\begin{array}{l}\text { El canal tradicional sigue teniendo mayor } \\
\text { preferencia en la categoría textil } \\
\text { minorista. "Gamarra es el principal canal, } \\
\text { concentrando más de un cuarto del gasto de la } \\
\text { categoría"(Kantar Worldpanel, 2018, párr.5). }\end{array}$ & $\begin{array}{l}12 \text { meses- Amenaza } \\
\text { 1-3 años - Amenaza } \\
\text { 3-5 años - Oportunidad }\end{array}$ \\
\hline $\begin{array}{l}\text { Socio } \\
\text { cultural } \\
\text { Ambiental }\end{array}$ & $\begin{array}{l}\text { El mercado peruano tiene mayor } \\
\text { predisposición a comprar productos premium } \\
\text { en la categoría de ropa y calzado al encontratar } \\
\text { beneficios superiores. Según Nielsen } \\
(2017) \text {,"Las categorías que más ventas registra } \\
\text { en la gama de lo premium son ropa y calzado } \\
(41 \%) \text { " (párr.6) }\end{array}$ & $\begin{array}{l}12 \text { meses- Oportunidad } \\
\text { 1-3 años - Oportunidad } \\
\text { 3-5 años - Oportunidad }\end{array}$ \\
\hline $\begin{array}{l}\text { Socio } \\
\text { cultural } \\
\text { Ambiental }\end{array}$ & $\begin{array}{l}\text { El consumidor peruano es muy exigente, } \\
\text { búsca productos de alta calidad a bajo } \\
\text { precio.Esto genera una menor lealtad de } \\
\text { marca, ya que están abiertos a cambiar por } \\
\text { obtener mejores precios. }\end{array}$ & $\begin{array}{l}12 \text { meses- Amenaza } \\
\text { 1-3 años - Amenaza } \\
\text { 3-5 años - Oportunidad }\end{array}$ \\
\hline $\begin{array}{l}\text { Socio } \\
\text { cultural } \\
\text { Ambiental }\end{array}$ & $\begin{array}{l}\text { Mayor tendencia a visitar centros comerciales } \\
\text { para comprar prendas de vestir, debido a la } \\
\text { gran expansión en los últimos años. Las } \\
\text { nuevas aperturas se estás realizando en zonas } \\
\text { de periféricas y en provincias. }\end{array}$ & $\begin{array}{l}12 \text { meses- Oportunidad } \\
\text { 1-3 años - Oportunidad } \\
\text { 3-5 años - Oportunidad }\end{array}$ \\
\hline $\begin{array}{l}\text { Socio } \\
\text { cultural } \\
\text { Ambiental }\end{array}$ & $\begin{array}{l}\text { Mayor interés de la población por conocer que } \\
\text { hay detrás de la marca, cuál es su aporte a la } \\
\text { sociedad. }\end{array}$ & $\begin{array}{l}12 \text { meses- Oportunidad } \\
\text { 1-3 años - Oportunidad } \\
\text { 3-5 años - Oportunidad }\end{array}$ \\
\hline $\begin{array}{l}\text { Socio } \\
\text { cultural } \\
\text { Ambiental }\end{array}$ & $\begin{array}{l}\text { La industria textil peruana cuenta con una } \\
\text { tradición milenaria. El algodón peruano es } \\
\text { reconocido en el mundo. }\end{array}$ & $\begin{array}{l}12 \text { meses- Amenaza } \\
\text { 1-3 años - Amenaza y } \\
\text { Oportunidad } \\
\text { 3-5 años - Oportunidad }\end{array}$ \\
\hline Tecnológico & $\begin{array}{l}\text { Mayor consumo en e-commerce. Un gran } \\
\text { sector de la población usa o está probando los } \\
\text { canales de venta virtuales debido a la } \\
\text { comodidad, rapidez y promociones que ofrece. } \\
\text { Un factor que impulsó esta tendencia es la } \\
\text { adaptación de los smartphones. }\end{array}$ & $\begin{array}{l}12 \text { meses- Oportunidad } \\
\text { 1-3 años - Oportunidad } \\
\text { 3-5 años - Oportunidad }\end{array}$ \\
\hline
\end{tabular}


(continuación)

\begin{tabular}{|c|c|c|}
\hline Tecnológico & $\begin{array}{l}\text { Incremento del uso de internet permite tener } \\
\text { mayor información sobre los productos y las } \\
\text { empresas; los usuarios pueden buscar } \\
\text { comentarios de otros consumidores e } \\
\text { información sobre la ética y trayectoria de las } \\
\text { empresas. }\end{array}$ & $\begin{array}{l}12 \text { meses- Oportunidad } \\
\text { 1-3 años - Oportunidad } \\
\text { 3-5 años - Oportunidad }\end{array}$ \\
\hline Tecnológico & $\begin{array}{l}\text { Disponibilidad de nuevas tecnologías permite } \\
\text { analizar y adminitrar la información sobre las } \\
\text { conductas de compra y dirigir mejorar sus } \\
\text { estrategias y campañas de marketing de } \\
\text { acuerdo al perfil de comprador. }\end{array}$ & $\begin{array}{l}13 \text { meses- Oportunidad } \\
\text { 1-3 años - Oportunidad } \\
\text { 3-5 años - Oportunidad }\end{array}$ \\
\hline
\end{tabular}

Fuente: Hill y Jones (2010)

Elaboración Propia

\subsubsection{Análisis de las fuerzas competitivas del sector industrial}

Según Hill y Jones (2010), el modelo de las cinco fuerzas de Porter ayuda a análizar el ambiente de la industria identificando las oportunidades y amenazas. Esta herramienta evalua el riesgo de ingreso de nuevos competidores, intensidad de la rivalidad entre competidores, poder de negociación de los compradores, poder de negociación de los proveedores y productos sustitutos. (p.42)

\section{Riesgo de ingreso de competidores potenciales - Baja}

Economías de escala: La industria de Fast Fashion tiene dominio sobre su cadena de valor para lograr costos competitivos. La fabricación de sus prendas se realiza en países en desarrollo donde la mano de obra es bastante económica. Además, realiza sus compras de materia prima de forma centralizada para obtener mejores costos y condiciones de compra.

Lealtad de la marca: el rápido cambio de tendencias y los precios competitivos hace que los consumidores sean menos leales a las marcas. Actualmente los líderes de la industria tratan de diferenciar su oferta ofreciendo las últimas tendencias rápidamente o lanzando colaboraciones con diseñadores. Uniqlo se enfoca en la innovación de sus prendas y el servicio a sus clientes dando un valor agregado.

Costo de cambio: es muy bajo, los clientes pueden cambiar fácilmente de marca con el objetivo que encontrar mejores precios o nuevos diseños. 
Regulaciones gubernamentales: actualmente no existen regulaciones que prohíban el ingreso de empresas de Fast Fashion a la mayoría de los países.

\section{Intensidad de la rivalidad entre competidores actuales -Alta}

Estructura competitiva de la industria: actualmente hay pocos actores en la industria de la Moda rápida, ya que se necesita bastante capital para lograr la economía de escala. Tomando en cuenta la variable de participación de mercado podríamos decir que se trata de una industria consolidada; sin embargo, es importante recalcar que la penetración en los mercados emergentes es reducida.

Demanda de la industria: los consumidores están dispuestos a pagar altas sumas de dinero por imagen; sin embargo, esta demanda es sensible a los factores económicos del país al no ser un gasto básico necesario. Asimismo, el crecimiento que tiene la industria demuestra un incremento de la demanda con la migración de los formatos habituales a las tiendas de Fast Fashion.

Condiciones de los costos: los costos fijos son altos, esto se debe a los grandes locales comerciales, su ubicación, la cantidad de personal requerida por tienda y los altos costos logísticos, haciendo que la rivalidad aumente.

Barreras para evitar salida: Los costos fijos de salida son altos, ya que la empresa tendría que liquidar a todos sus colaboradores que constituye gran parte de estructura de gastos. Por otro lado, no hay inversión en activos específicos.

\section{Poder de negociación de los compradores - Baja}

Los clientes no son una amenaza ya que generan compra minorista. Asimismo, no son capaces de agruparse o realizar una integración vertical hacia atrás lo que les da muy poco poder de negociación.

\section{Poder de negociación de los proveedores - Baja}

Hay dos proveedores claves en la industria de la moda rápida, las fábricas aliadas y los productores de materia prima. Estos dos actores en su mayoría provienen de países en vías de desarrollo, los cuales están dispuestos a ofrecer muy buenos términos de compras y bajos costos sacrificando las condiciones laborales de sus empleados a cambio de trabajar con empresas trasnacionales de la moda. 
Existe un riesgo de integración hacía atrás, debido al gran volumen que manejan. Zara cuenta con fábricas propias en España y países cercanos.

Existe bajo costo de cambio de proveedor en la compra de materia prima si la calidad de la misma es similar. Por otro lado, existe un alto costo de cambio en la contratación de fábrica debido a los estándares y procesos de control que manejan para asegurar que el producto final cumpla con todos sus estándares.

\section{Productos sustitutos - Baja}

Los productos sustitos más relevantes son las tiendas por departamento, que ofrecen una experiencia de compra similar a las cadenas de moda rápida, las cuales están reaccionando activamente a los nuevos competidores fortaleciendo sus marcas propias y canal online.

También se encuentran las boutiques, establecimientos pequeños enfocados a vender cierto tipo de prendas de vestir.

Tiendas de ropa del canal tradicional que venden prendas genéricas o imitaciones del mercado local, como Gamarra.

En conclusión, el poder de la industria de acuerdo a las fuerzas de Porter es alto, al ser un sector atractivo con bastante manejo de sus principales actores. La fuerza más complicada es la rivalidad entre los competidores actuales lo cual exige a las empresas de la industria una constante mejora de su oferta de valor.

\subsubsection{Determinación y Sustentación de las Oportunidades y Amenazas} Oportunidades

- Todos los indicadores macroeconómicos son positivos y proyectan un mercado próspero. Este es un buen indicador para cualquier empresa que quiera ingresar al país, ya que es la suma de variables claves del desarrollo de la economía como el consumo de familias, el consumo del gobierno, inversiones y exportaciones.

- Crecimiento significativo del sector retail. Fast Retailing ingresaría a este sector que los últimos años ha tenido un desarrollo importante. 
- El cliente peruano tiene mayor predisposición a comprar productos premium de calidad en la categoría de ropa y calzado. Los productos de Fast Retailing se considerarán premium en el Perú debido a su ticket de compra y calidad.

- Mayor tendencia a visitar centros comerciales para comprar prendas de vestir. Estos centros serán la ubicación potencial de las tiendas de la compañía, los cuales se harán rápidamente conocidas debido al alto tráfico de personas.

- Aumento del e-commerce. Es una ventaja para la marca, ya que tienen mucha experiencia en este canal de ventas y sería fácil implementarlo en el mercado local.

- Mayor búsqueda y análisis de los clientes antes de realizar una compra. Es una oportunidad ya que sus productos tienen diferencias importantes y buena crítica por parte de sus usuarios. Además, la empresa cuenta con una ejemplar trayectoria a nivel mundial debido a su innovadora propuesta.

- Crisis política debido a los enfrentamientos entre el poder ejecutivo y legislativo. La inestabilidad política pone en riesgo el avance económico ya que proyecta una imagen de inseguridad para los inversores. Igualmente, genera desconfianza en la población que afecta el consumo masivo.

- Rivalidad en el sector minorista textil moderno. Existe bastante competencia de marcas que tienen mayor posicionamiento en el mercado occidental, lo cual va a resultar una amenaza para el ingreso exitoso de UNIQLO en Perú.

- Canal tradicional sigue liderando en el mercado minorista textil. La mayor parte de la población aún compra en centros como Gamarra por hábito. Esta costumbre puede ser una limitante para el desarrollo de UNIQLO en el país.

- Posicionamiento de la industria textil peruana en el país. Actualmente se puede encontrar prendas de buena calidad fabricadas en el sector local. 
- Los niveles socioeconómicos C y D representan más del $60 \%$ de la población. Los ingresos mensuales de la mayoría de la población dificultan la compra de prendas de vestir ofrecidas por la compañía. 


\section{CAPÍTULO II: FORMULACIÓN DE LA ESTRATEGIA}

En este capítulo se formulará la estrategia para UNIQLO, marca seleccionada para el ingreso de Fast Retailing al Perú.

\subsection{Desarrollo y sustentación de la Matriz EFI}

David (2017), La Matriz EFI es un instrumento para formular estrategias que resumen y evalúan las fuerzas y debilidades más importantes dentro de las áreas funcionales de una empresa (p. 149).

Tabla 2.1

Matriz EFI

\section{Valor Clasificación ponderado}

\begin{tabular}{|l|r|r|r|}
\hline Fortalezas & \multicolumn{3}{|c|}{} \\
\hline Cultura sólida alienada a los objetivos. & 0.10 & 4 & 0.4 \\
\hline Cadena de valor controlada mediante el modelo SPA & 0.08 & 4 & 0.32 \\
\hline Desarrollo de materiales innovadores & 0.12 & 4 & 0.48 \\
\hline Nototoriedad de la marca internacionalmente. & 0.07 & 3 & 0.21 \\
\hline $\begin{array}{l}\text { Propuesta de valor diferenciada brindando ropa básica } \\
\text { de calidad a excelentes precios. }\end{array}$ & 0.12 & 4 & 0.48 \\
\hline Sólido canal de e-commerce en el mundo. & 0.06 & 4 & 0.24 \\
\hline Se dirige a un segmento amplio. & 0.05 & 4 & 0.20 \\
\hline Debilidades & & & \\
\hline Desconocimiento de la marca en sudamérica. & 0.08 & 1 & 0.08 \\
\hline Productos se adecuan a las necesidades asiáticas. & 0.07 & 2 & 0.14 \\
\hline Logística lente comparada con Inditex. & 0.08 & 1 & 0.08 \\
\hline Dificultad para posicionar la marca en occidente. & 0.1 & 1 & 0.1 \\
\hline No vender ropa de modas pasajeras. & 0.07 & 2 & 0.14 \\
\hline & 1 & 2.87 \\
\hline
\end{tabular}

Fuente: David (2017)

Elaboración propia

El valor ponderado de 2,87 supera al promedio, lo cual indica que le empresa cuenta con capacidades sólidas para enfrentar su entorno competitivo. 


\subsection{Desarrollo y sustentación de la Matriz EFE}

Según David (2017), una Matriz de evaluación del factor externo (EFE) permite a los estrategas resumir y evaluar la información económica, social, cultural, demográfica, ambiental, política, gubernamental, legal, tecnológica y competitiva (p. 110).

Tabla 2.2

Matriz EFE

Valor Clasificación

Oportunidades

Indicadores macroeconómicos positivos para los próximos años. Incremento del canal de venta online.

Crecimiento del sector retail del $9 \%$ en el 2018.

Consumidores más exigentes, informados y conscientes.

Predisposición a comprar productos premium en la categoría de ropa.

Mayor tendencia a visitar centros comerciales.

Amenazas

Crisis política que genera inestabilidad y desconfianza.

Competidores fuertes con marcas consolidadas en el Perú.

Canal tradicional es el líder del sector textil minorista.

Los niveles socioeconómicos C y D representan el $66 \%$.

Fuente: David (2017)

Elaboración propia

El valor de 2.98 concluye que la empresa sabe responder bien a las oportunidades del mercado y evitar los factores negativos de su contexto.

\begin{tabular}{|r|r|r|}
\hline 0.12 & 3 & 0.36 \\
\hline 0.1 & 4 & 0.4 \\
\hline 0.12 & 3 & 0.36 \\
\hline 0.06 & 4 & 0.24 \\
\hline 0.08 & 4 & 0.32 \\
\hline 0.06 & 4 & 0.24 \\
\hline 0.12 & & 0 \\
\hline 0.14 & 2 & 0.24 \\
\hline 0.1 & 3 & 0.42 \\
\hline 0.1 & 2 & 0.2 \\
\hline 1 & 2 & 0.2 \\
\hline & & 2.98 \\
\hline
\end{tabular}

Elaboración propia 


\subsection{Matriz de las Estrategias Genéricas}

Según Hill y Jones (2010), las estrategias de negocios son el conjunto de acciones que las empresas realizan para crear ventaja competitiva sobre sus rivales con el objetivo de mejorar su posicionamiento mediante el uso eficiente de sus recursos y actividades claves. (p.145)

Figura 2.1

Matriz de las Estrategias Genéricas

\section{VENTAJA ESTRATÉGICA}

Exclusividad percibida por el cliente

Posición de Costo Bajo

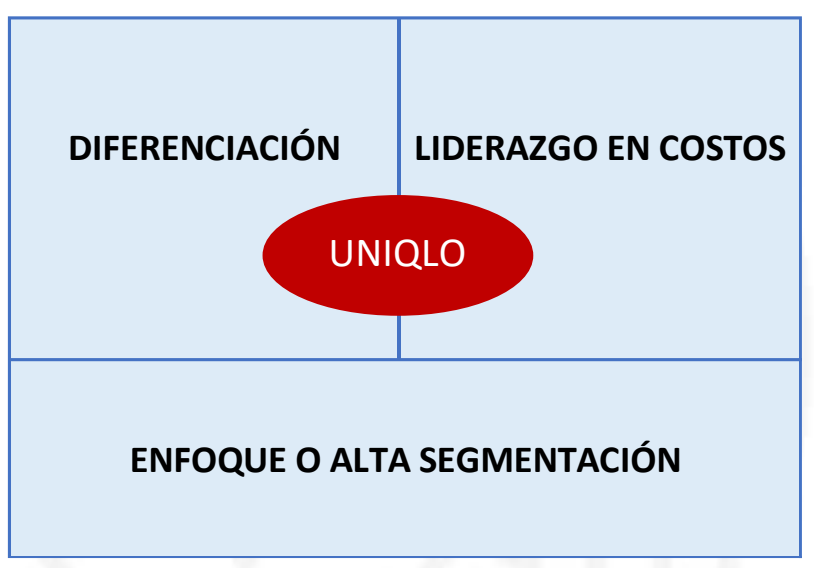

Fuente: Porter (2009)

Elaboración propia

\section{Liderazgo en Costos:}

UNIQLO ha logrado tener liderazgo en costos gracias al control de toda su cadena de valor. Al realizar una estrategia vertical hacia atrás y suprimir los intermediarios ha mejorado la rentabilidad de su negocio y ha conseguido costos muy competitivos, que le permite ofrecer a sus clientes prendas de buen desempeño a excelente precio.

Esta estrategia necesita una revisión continua para siempre mejorar la eficiencia y actualizar su tecnología para no quedarse atrás.

\section{Diferenciación:}


La propuesta de valor de la marca es muy diferente a la de sus competidores más cercanos. Mientras que en la industria de Fast Fashion vende moda, UNIQLO vende tecnología y calidad; su enfoque es brindar ropa casual básica que perdure en el tiempo. Además de sus excelentes productos, brinda una buena atención en sus tiendas que se complementa con una retroalimentación constaste de sus clientes para mejorar su satisfacción y desarrollar textiles innovadores. Asimismo, la compañía enfoque social que le da un valor agregado a la marca.

Con esto concluimos que UNIQLO tiene una diferenciación ampliada ya que ofrece al mercado ropa de alta calidad de buenos insumos e innovaciones textiles a la mitad de lo que costaría en otra tienda gracias a su estructura de costos. 


\subsection{Matriz FODA}

David (2017), es una herramienta que ayuda a crear cuatro tipos de estrategias: estrategias de fortalezas y oportunidades (FO), estrategias de debilidades y oportunidades (DO), estrategias de fortalezas y amenazas (FA) y estrategias de debilidades y amenazas (DA). (p.200).

\section{Tabla 2.3}

\section{Matriz FODA}

\section{portunidades}

1 Indicadores macroeconómicos positivos para los próximos años.

2 Incremento del canal de venta online.

3 Crecimiento del sector retail del $9 \%$ en el 2018 .

4 Consumidores más exigentes, informados y conscientes.

5 Predisposición a comprar productos premium en categoría de ropa.

6 Mayor tendencia a visitar centros comerciales.

\section{Amenazas}

1 Crisis política que genera inestabilidad y desconfianza.

2 Competidores fuertes con marcas consolidadas en el Perú.

3 Canal tradicional es el líder del sector textil minorista.

4 Los niveles socioeconómicos C y D representan el $66 \%$.

Fuente: David (2017)

Elaboración propia

N

\begin{tabular}{|c|c|}
\hline Fortalezas & Debilidades \\
\hline $\begin{array}{l}1 \text { Propuesta de valor diferenciada brindando ropa básica e } \\
\text { innovadora de calidad a precio razonable con servicio. } \\
2 \text { Cultura sólida enfocada en los clientes y objetivos. } \\
3 \text { Cadena de valor contralada mediante el Modelo SPA. } \\
4 \text { Centros para desarrollar textiles tecnológicos. } \\
5 \text { Notoriedad de la marca internacional por su gran éxito. } \\
6 \text { Sólido canal de e-commerce en el mundo. } \\
7 \text { Se dirige a un segmento amplio. }\end{array}$ & $\begin{array}{l}1 \text { Desconocimiento de la marca en Sudamérica } \\
2 \text { Prendas de vestir adaptada al mercado Asiático. } \\
3 \text { Logística lenta comparada con Inditex. } \\
4 \text { No vende ropa de las últimas tendencias de moda, se enfoca } \\
\text { en prendas básicas. } \\
5 \text { Dificultad para posicionar la marca en el mercado occidental. }\end{array}$ \\
\hline Estrategias FO & Estrategias DO \\
\hline $\begin{array}{l}\text { F6O2 Implentar y desarrollar el canal de ventas online en el Perú } \\
\text { aprovechando su experiencia y conocimiento en esta área. }\end{array}$ & \multirow[t]{2}{*}{$\begin{array}{l}\text { Contratar una reconocida agencia de publicidad peruana que } \\
\text { D1O5 trasmita la propuesta de valor de sus productos y haga enfásis } \\
\text { en sus precios razonables. }\end{array}$} \\
\hline $\begin{array}{l}\text { Incorporar embajadores de marca peruanos de distintas } \\
\text { edades y rubros que confirmen su filosofía 'Made for all' }\end{array}$ & \\
\hline $\begin{array}{l}\text { F4O4 Evaluar a los colabores de tienda en su conocimiento sobre las } \\
\text { diferencias y beneficios de sus prendas innovadoras. }\end{array}$ & $\begin{array}{l}\text { Ubicar sus primeras tiendas en los centros comerciales más } \\
\text { D106 representativos para ganar presencia de marca y tráfico de } \\
\text { personas. }\end{array}$ \\
\hline Estrategia FA & Estrategia DA \\
\hline \multirow{2}{*}{$\begin{array}{l}\text { Desarrollar un plan de capacitación constante para todos } \\
\text { F2A3 los colaboradores para que se alineen a la cultura y } \\
\text { objetivos de la compañía. }\end{array}$} & $\begin{array}{l}\text { D5A4 Realizar un estudio de mercado al consumidor peruano para } \\
\text { determinar el segmento objetivo y el portafolio adecuado. }\end{array}$ \\
\hline & D4A2 Implementar un programa de CRM para fidelizar a los clientes \\
\hline $\begin{array}{l}\text { F5A2 comunicar la trayectoria y nuevos proyectos de la } \\
\text { compañía en el país. }\end{array}$ & $\begin{array}{l}\text { Desarrollar un colección con hecha con algodón peruano de } \\
\text { D2A3 calidad, que una el sentimiento patriotra con el diseño avanzado } \\
\text { de la marca, para crear un producto insuperable para todos los } \\
\text { peruanos. }\end{array}$ \\
\hline
\end{tabular}
peruanos. 


\subsection{Definición y Sustentación de la Visión, Misión y Políticas}

En este punto de planteará la Visión, Misión y Políticas para Fast Retailing internacional. Misión Diseñar y comercializar prendas de vestir y accesorios esenciales de alta calidad y duraderos en el tiempo y con el objetivo de enriquecer la vida de todas las personas, sin importar su edad y género a nivel internacional.

Visión Ser una empresa líder de la industria textil siendo reconocidos mundialmente por la calidad e innovación de sus productos con precios comparativamente bajos y su compromiso con la sociedad.

\section{Políticas:}

- Tener como prioridad la satisfacción de los clientes en todas las acciones y decisiones corporativas.

- Buscar siempre la excelencia para obtener los resultados sobresalientes.

- Enfocarse en la contribución y desarrollo de la sociedad actuando con ética e integridad.

- Poseer una actitud receptiva al cambio para asumir los nuevos retos del entorno.

- Asegurar que toda la fuerza laboral este empoderada y capacitada.

- Dar prioridad a todos los puntos de contacto que se tenga que los clientes para asegurar su satisfacción total.

- Constituir y desarrollar una cultura organizacional sólida.

- Buscar siempre la eficiencia para lograr mayor rentabilidad.

- Aprender de los fracasos, para tomar mejores decisiones futuras.

\subsection{Definición de los Objetivos Estratégicos de la Empresa}

- Duplicar los ingresos en el Perú en el segundo año de operaciones impulsado por la maduración de las tiendas inauguradas y la apertura de nuevos locales.

- Aumentar la utilidad neta en $6 \%$ en 3 años mediante la disminución de costos por la economía de escala y mejorando la eficiencia en la cadena de suministro. 
- Aumentar la rentabilidad por cliente en $10 \%$ en 3 años mediante un programa de CRM para fidelizar a los consumidores.

- Posicionar la marca en el Perú como la líder en ropa de mejor calidad a precios accesibles mediante embajadores de marca peruanos y campañas publicitarias digitales en 4 años.

- Diferenciar la experiencia de compra frente a sus competidores brindando un servicio de calidad en 2 años, mediante un plan de capacitación integral para la fuerza de venta.

- Lograr una participación del 5\% del canal de ventas online al culminar el primer año de operaciones, aprovechando su infraestructura de software y experiencia en otros mercados.

- Lanzar en el país dos innovaciones textiles tecnológicas al año para motivar el interés de sus clientes por visitar sus tiendas.

- Reducir el tiempo de envío de las fábricas al punto de venta en $20 \%$ mediante inversión tecnológica en 18 meses.

- Apertura de 4 tiendas de UNIQLO en los primeros dos años en los principales centros comerciales del Perú.

- Tener dos capacitaciones al mes para los colaboradores de tienda.

- Obtener un resultado promedio de 80 sobre 100 en las evaluaciones de desempeño realizadas a los colaboradores en dos años.

- Lograr una aprobación del $85 \%$ en las encuestas de clima laboral realizada a los dependientes en tres años.

\subsection{Redefinición de las UEN (Unidad Estratégica de Negocios) o creación de nuevas UEN}

Actualmente las unidades son: UNIQLO Japón, UNIQLO Internacional, Marcas Globales y GU.

La propuesta de cambio es dividir la unidad UNIQLO Internacional en dos: UNIQLO Internacional Occidente y UNIQLO Internacional Oriente; debido a que ambas poblaciones se han desarrollado de forma distinta durante miles de años dando como resultado diferentes gustos en aspectos estéticos y estilo de vida. 
Según el diagnostico, no existe una estrategia diferenciada para el mercado occidental. El objetivo de esta nueva división es brindar mayor foco e implementar cambios para satisfacer las necesidades de esta área geográfica en el cual lnditex y H\&M están bastante desarrollados.

Esta división es importante para el ingreso al Perú, ya que históricamente el mercado peruano ha aceptado con mucha facilidad las marcas exitosas en los Estados Unidos y Europa. Asimismo, UNIQLO tendría un equipo enfocado en el seguimiento del ingreso al mercado peruano, lo cual es crucial para el éxito.

Para concluir, las demás UEN me parecen inmejorables, ya que son el número óptimo para no saturar la alta dirección de la compañía.

\subsection{Propuesta y sustentación de Estrategias en el ambiente Global, Corporativas, de Negocios y Funcionales}

\section{Estrategia Global:}

La estrategia propuesta es la global ya que se concentra en mejorar la rentabilidad aprovechando sus económias de escala, lo cual les genera una ventaja de costos que se trasladada al precio final de los clientes. Para el ingreso a Perú, UNIQLO traería los productos que vende en todo el mundo a un excelente precio. La adaptación sería baja ya que solo debe seleccionar el portafolio adecuado de prendas y accesoroios y realizar pequeños cambios para adaptarse al mercado local. 
Figura 2.2

Matriz de Estrategia Global

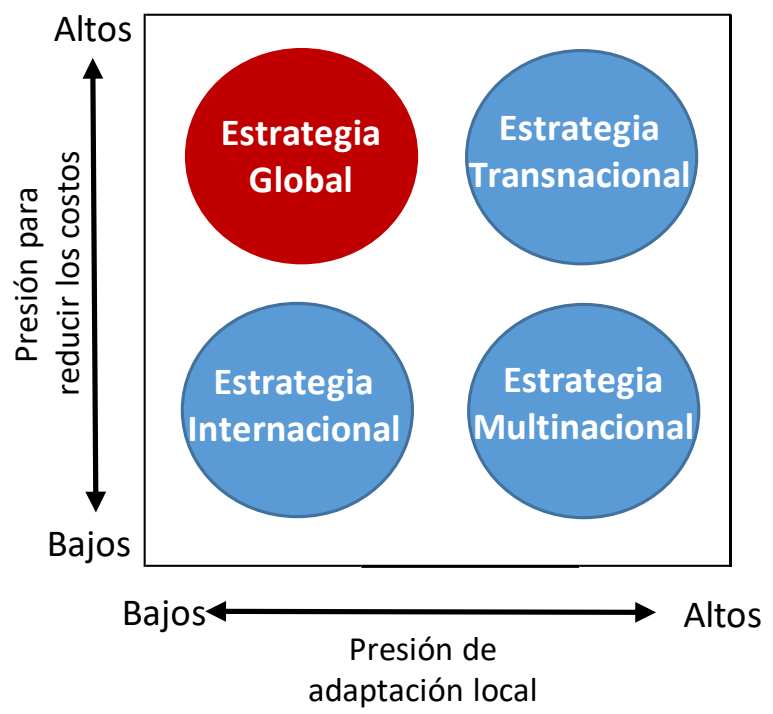

Fuente: Hill y Jones (2010)

Elaboración propia

\section{Estrategias Corporativas}

Integración vertical: Fast Retailing expandió sus operaciones hacia atrás al implementar el modelo SPA. La empresa se encarga de desarrollar nuevos materiales, diseñar las prendas y negociar las compras a volumen con los productores. Una propuesta es implementar fábricas propias para tener un manejo más directo.

Integración Horizontal: Fast Retailing ha realizado diferentes adquisiciones de empresas similares de la industria. En el año 2004 compró Theory una tienda de ropa de New York, que les ayudó a entrar a Estados Unidos y a acceder a una red de contactos en el país. Esta estrategia se puede replicar para ingresar a nuevos países, ya que te brinda conocimiento sobre el sector local y es de gran ayuda cuando el mercado es muy distinto a los trabajados anteriormente. En Perú, se podría iniciar operaciones comprando una tienda departamental que quieras salir del país.

Outsourcing Estratégico: Toda la producción de prendas está a cargo de fábricas asociadas que se encuentran en su mayoría en China. Esta táctica se debe mantener ya que le da ventaja de costos. 
Diversificación: la compañía ha tenido diversificación relacionada y no relacionada. La diversificación relacionada es ideal para aprovechar las competencias y compartir recursos y capacidades. Se sugiere solo enfocarse en la diversificación relacionada para consolidar la empresa en el sector textil. Ingresar a otros sectores en esta etapa distraería mucho a los directivos, cuando deben estar enfocados en ser la empresa número uno de la industria textil.

Alianzas estratégicas: Fast Retailing ha formado joint ventures con empresas locales al ingresar nuevos países. Esta estrategia se debe seguir replicando ya que el riesgo de entrada disminuye al tener un aliado que conoce el mercado y la industria local.

También se propone seguir desarrollando líneas de ropa en conjunto con diseñadores reconocidos, con la finalidad de captar nuevo público.

\section{Estrategias de Negocio}

La estrategia de enfoque diferenciación más liderazgo en costos se debe seguir manejando, ya que es el factor clave que ha logrado el crecimiento exponencial de la empresa. Su propuesta se ha alejado de la moda y se ha enfocado en buscar soluciones de valor a los consumidores que buscan productos básicos a un precio razonable. Es importante seguir comunicando este enfoque en todas las actividades claves de la empresa para mantener su posición competitiva en el sector.

\section{Estrategias Funcionales}

En este punto se seleccionará las actividades claves de la cadena de valor y se propondrán las estrategias más adecuadas para cada una.

I+D: la principal estrategia que se a perfeccionar es la capacidad de respuesta al cliente identificando sus necesidades. Los consumidores deben nutrir con información los centros de innovaciones de la marca. La segunda estrategia es la innovación superior que busque nuevos materiales y procesos.

Fabricación: se debe enfocar en la eficiencia superior al aprovechar las economías de escala y economías de aprendizaje para mantener una estructura de costos reducida. 
Comercialización y Marketing: se debe orientar a la calidad para ofrecer locales limpios con ambiente agradable y un servicio amable. Con respecto al marketing, las campañas de publicidad deben ser excelentes desde su formulación hasta sus resultados logrado. 


\section{CAPÍTULO III: IMPLEMENTACIÓN ESTRATÉGICA}

3.1 Evaluación del rediseño o no rediseño de la estructura organizacional de la empresa (Sustento)

Figura 3.1

Estructura Organizacional

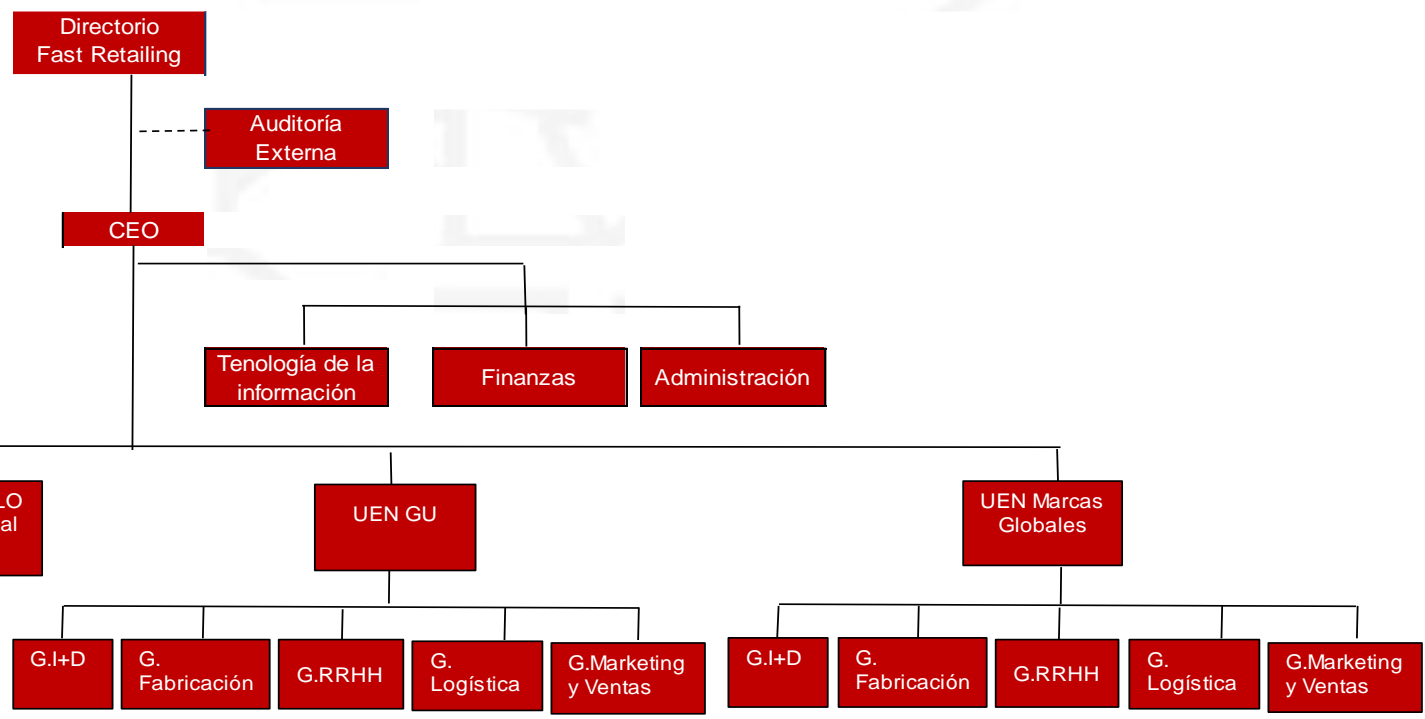

Fuente: Hill y Jones (2010)

N Elaboración propia 
En base al análisis realizado, se propone una estructura multidivisional. Para la marca UNIQLO se plantea una estructura matricial que permita una integración intensiva entre las áreas funcionales y las UEN UNIQLO Japón, UNIQLO Occidente y UNIQLO Oriental; con el objetivo de fomentar la innovación y acelerar el crecimiento de cada división geográfica.

Asimismo, el responsable de la UEN UNIQLO Occidente en combinación con las gerencias funcionales deben asegurar la entrada satisfactoria de Uniqlo a la ciudad de Lima mediante la elaboración de estrategias y planes de acción que permitan a la marca iniciar operaciones de forma eficiente; con la ventaja de una estructura que brinda flexibilidad y rapidez.

Por otro lado, las unidades GU y marcas globales cuentan con una estructura funcional al agrupar sus gerencias por funciones de negocio.

Cabe recalcar, que el presente organigrama cuenta con tres áreas que dan soporte a todas las unidades de negocio, las cuales son tecnología de la información, finanzas y administración.

\subsection{Propuesta de cambios para mejorar la implementación de estrategias en la empresa}

Según Hill y Jones (2010), La implementación de la estrategia usa la estructura organizacional para coordinar e integrar los esfuerzos de los colaboradores de todos los niveles, junto con los sistemas de control y la cultura para ejecutar un modelo de negocio exitoso. (p.380)

Tomando en cuenta lo antes mencionado, la primera propuesta es formular un bono anual por cumplimiento de metas a las áreas claves de la organización, para que logren una mayor eficiencia y calidad en su trabajo y estén alineados al objetivo de la empresa.

La segunda propuesta es implementar indicadores de gestión para todas las áreas funcionales que midan la productividad de cada puesto. Además, se debe planificar continuamente reuniones de retroalimentación en las que se aconseje o felicite la gestión entre trabajadores y gerentes. 
Para finalizar se propone la creación del área de Clima y Cultura con el objetivo de desarrollar valores y comportamientos positivos que conlleve a un mayor compromiso y motivación de los colaboradores. Esta medida es importante, ya que una cultura bien cultivada se puede convertir en una ventaja importante que asegure el crecimiento y éxito de la empresa. 


\section{CAPÍTULO IV: CONTROL ESTRATÉGICO}

\subsection{Diseño de un Mapa Estratégico de Control para la empresa}

Según Roncancio (2018), el mapa estratégico es una representación gráfica de la empresa, que permite visualizar los procedimientos que aportan valor mediante un conjunto de relaciones de causa efecto. Por esta razón esta herramienta es clave para establecer los objetivos estratégicos de Fast Retailing en cuatro perspectivas.

Figura 4.1

Mapa Estratégico de Control

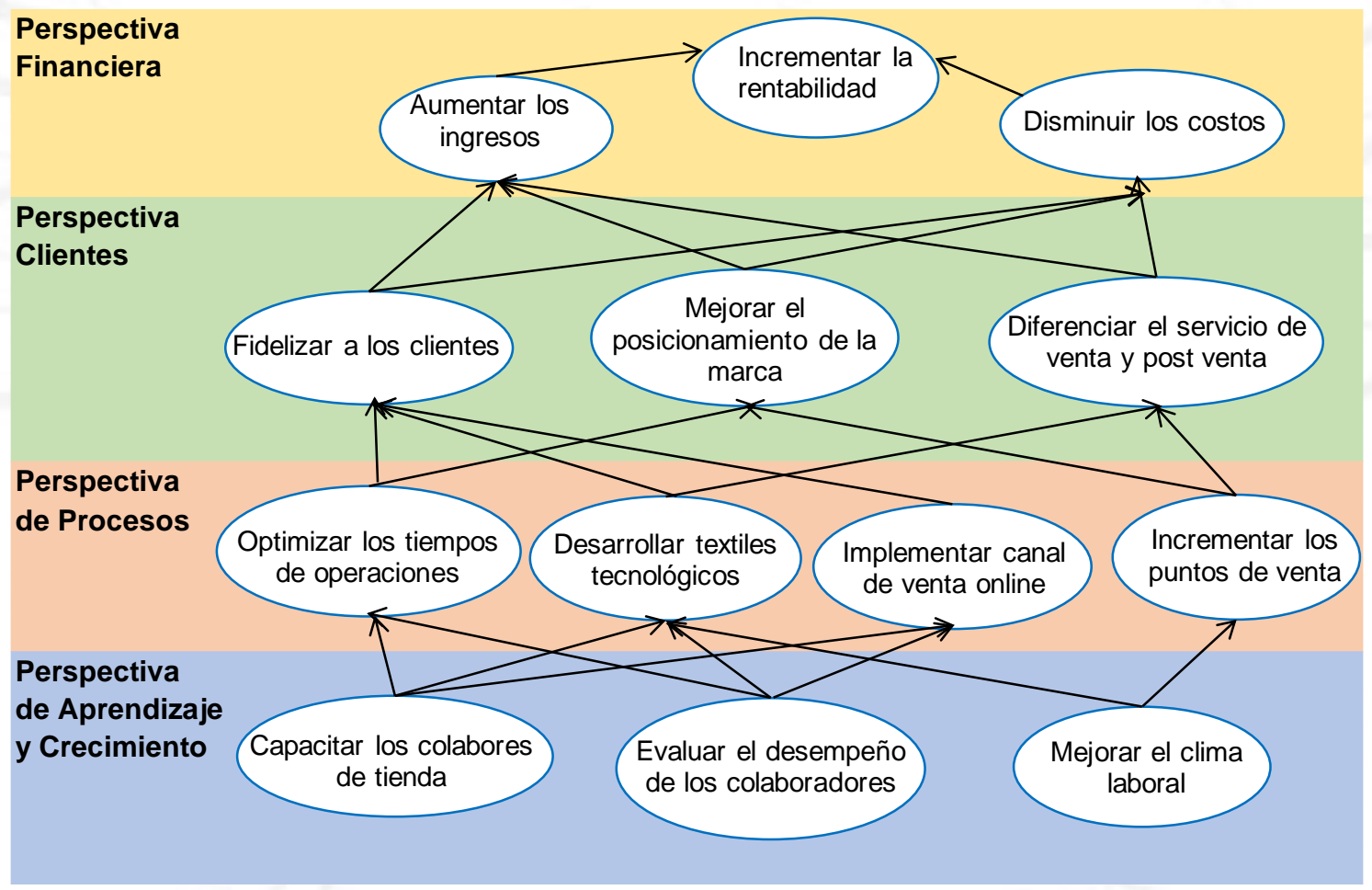

Fuente: Kaplan y Northon (2004)

Elaboración propia 


\subsection{Desarrollo de un Cuadro de Mando Integral con un mínimo de 10 índices de gestión (Sustento) (Cuatro Perspectivas)}

Según Alvarez (2013), los indicadores son medidores que permiten evaluar el desempeño de la empresa, facilitar la toma de decisiones estrategicas y aplicar las medidas correctivas en caso se requiera.(p.8)

En consiguiente, se formularan los KPI para cada perspectiva con la finalidad de analizar el cumplimiento de los objetivos de Fast Retailing.

Tabla 4.1

Cuadro de Mando Integral

\begin{tabular}{|c|c|c|c|}
\hline Perspectiva & Objetivo & \multicolumn{2}{|c|}{ Porcentajelndicador } \\
\hline \multirow{3}{*}{$\begin{array}{l}\text { Perspectiva } \\
\text { Financiera }\end{array}$} & Aumentar los ingresos & $30 \%$ & Venta anuales \\
\hline & Incrementar la rentabilidad & $40 \%$ & Utilidad Neta \\
\hline & Disminuir los costos & $30 \%$ & Costo anuales \\
\hline \multirow{4}{*}{$\begin{array}{l}\text { Perspectiva de } \\
\text { Cliente }\end{array}$} & Fidelizar a los clientes & $30 \%$ & Nivel de satisfacción del cliente (Encuestas) \\
\hline & Mejorar el posicionamiento de la marca & $30 \%$ & Posicionamiento de la marca (Encuestas) \\
\hline & Diferenciar el servicio de venta y post & \multirow{2}{*}{$15 \%$} & \multirow{2}{*}{ Número de devoluciones de producto } \\
\hline & venta & & \\
\hline \multirow{4}{*}{$\begin{array}{l}\text { Perspectiva de } \\
\text { Procesos }\end{array}$} & Optimizar los tiempos de operaciones & $30 \%$ & Período promedio de existencias (días) \\
\hline & Desarrollar textiles tecnológicos & $20 \%$ & Lanzamiento de innovaciones al año \\
\hline & Incrementar los puntos de venta & $30 \%$ & Número de tiendas aperturadas al año \\
\hline & Implementar el canal de venta online & $20 \%$ & Participación de venta online \\
\hline \multirow{4}{*}{$\begin{array}{l}\text { Perspectiva de } \\
\text { Aprendizaje y } \\
\text { crecimiento }\end{array}$} & Mejorar el clima organizacional & $35 \%$ & Encuestas de Clima laboral \\
\hline & Evaluación de desempeño de los & \multirow{2}{*}{$35 \%$} & \multirow{2}{*}{ Resultado de evaluaciones } \\
\hline & colaboradores & & \\
\hline & Capacitar los colaboradores de tienda & $30 \%$ & Número de capacitaciones en el mes \\
\hline
\end{tabular}

Fuente: Kaplan y Northon (2004)

Elaboración propia 


\section{CONCLUSIONES}

Después del diagnóstico, podemos concluir que Fast retailing ha logrado desarollar una oferta de valor diferente e innovadora que los grandes lideres de la moda no han podido. Este resultado se debe a la aplicación de la estrategia de Diferenciación Ampliada basada en su mejorado modelo SPA que obtiene una estructura de costos baja asegurando la calidad en toda la cadena de valor.

Otra clave del éxito de Fast Retailing es la clara extensión de su misión y visión en todas las decisiones y acciones de sus áreas funcionales. La empresa está completamente alineada a su ser, lo cual la fortalece y diferencia de otros actores en la industria. Un claro ejemplo de esto es la amplia segmentación de UNIQLO, que tiene como finalidad brindar ropa de alta calidad con precios comparativamente bajos a un público masivo, demostrando su compromiso con la sociedad.

El análisis externo demostró que existen varias oportunidades para que la compañía pueda desarrollarse en el Perú. Sin embargo, debido a las condiciones sociales y económicas del país y el ticket de venta de la marca, inicialmente solo se podría dirigir a los sectores socioeconómicos A y B. Considero que en tres años con el desarrollo del país y el posicionamiento de la marca en el mundo, Fast Retailing cumplira con su objetivo de masificar sus prendas de lujo en el Perú.

Para finalizar se puede concluir que la marca, requiere un enfoque distinto para el mercado occidente, especialmente en Estados Unidos, un país bastante consumista que no se siente muy atraído por prendas de vestir básicas de larga duración. Además, esta zona cuenta con un fuerte posicionamiento de marcas lideres en el sector, que tienen mucha experiencia y puntos de venta distribuidos estrategicamente. 


\section{RECOMENDACIONES}

Se sugiere que la marca se enfoque en posicionarse en los Estados Unidos, ya que es un mercado referente para muchos países de latinoamérica. Con este objetivo logrado, el éxito mundial de la marca será más fácil y varios países estarán expectantes de la llegada de la tienda.

Asimismo propongo que se postergue el ingreso de la marca al Perú para el año 2021. Tiempo en el cual la marca podrá expandirse y llegar a los mercados más atractivos y encontrar la estrategias clave para llegar al éxito en los países occidentales.

De igual manera, se recomienda flexibilizar el proceso de fabricación y diseño en dos partes: una estándar, manteniendo los parámetros actuales, es decir, muy estructurada pero poco flexible; y otra que permita cambios y planificación con un mes de anticipación, sin sacrificar calidad, esto aumentaría los costos pero le daria una ventaja a la empresa permitiendo responder velozmente a los cambios inesperados en la demanda.

Este cambio se lograría con la implementación de fábricas propias que estarían preparadas para actuar con rapidez cuando se requiera

De igual manera, en la parte de marketing se recomienda seguir invirtiendo en embajadores de marca conocidos mundialmente, ya que esta estrategia les ha permitido dar a conocer la marca a nuevos mercados potenciales.

Por último, se sugiere a Fast Reatailing y a todas las marcas del sector textil minorista enfocarse en la sustentabilidad de sus prendas, ya que cada vez los consumidores son más conscientes del impacto de sus acciones en el medio ambiente. 


\section{REFERENCIAS BIBLIOGRÁFICAS}

Alvarez, M. (2013). Cuadro de mando retail: Los indicadores clave (KPI) de los comercios altamente efectivos. Barcelona: PROFIT.

CCL. (19 de septiembre del 2018). CCL estima crecimiento del sector retail hasta en 9\% al cierre del 2018. Perú 21. Recuperado de https://peru21.pe/ economia/cclestima-crecimiento-sector-retail-9-cierre-2018-429201

David, F. R. (2017). Conceptos de Administración Estratégica. (15. Ed.). México, D.F.: Pearson.

Fast Retailing (29 de junio del 2018). Customer Feedback and Product improvements. Fast Retailing. Recuperado de https://www.fastretailing.com/eng/sustainability /pro ducts/customers.html

Hill, C.W.L., y Jones, G. R. (2010) Administración Estratégica: un enfoque intregral. México: Cengage Learning.

Hitt, M. A., Ireland, R. D., y Hoskisson, R. E., Mascaro, S.P., y Súarez, M. M. P. (2015). Administración estratégica: Competitividad y globalización: conceptos y casos. (11. Ed.). México, D.F.: Cenage Learning.

Ipsos Perú (28 de Agosto del 2013). El 55\% de los hogares urbanos pertenecen a la clase media y alta. Perú 21. Recuperado de https://peru21.pe/economia/55hogares-urbanos-pertenece-clase-media-alta-121849

Kantar Worldpanel. (21 de febrero del 2018). Gamarra es el principal canal de compra de ropa en Perú. Recuperado de https://www.peru-retail.com/gamarra-principalcanal-de-compra-ropa-peru/

Kaplan , R., y Norton, D. (2004). Mapas estratégicos . Barcelona: Gestión 2000.com.

Nielsen. (2017). Categorías premium de ropa y calzado y electrónicos personales las más vendidas en Perú. Recuperado de https://www.nielsen.com/pe/es/insights/article/2017/categorias-premium-deropa-y-calzado-y-electronicos-personales-las-mas-vendidas-en-peru

Osterwalder, A., y Pigneur, Y. (2013). Business model generation: A handbook for visionaries, game changers, and challengers.

Perú Retail (16 de agosto de 2018). Uniqlo busca potenciar sus ventas online en todo el mundo. Recuperado de https://www.peru-retail.com/uniqlo-ventas-online/

Porter, M. (2009). Estrategia Competitiva. Madrid: Ediciones Piramides. 
Rossini, R. (11 de diciembre del 2014). BCR: Normas de protección al trabajador en realidad lo afectan lanzándolo a la informalidad. Gestión. Recuperado de https://gestion.pe/economia/bcr-normas-proteccion-trabajador-realidad-afectanlanzandolo-informalidad-86343

Robbins, S., y Coulter, M. (2014). Administración. México: Pearson Educación.

Roncancio, G. (26 de Noviembre del 2018). ¿Qué es un mapa estratégico en el Balanced Scorecard y como se hace? Recuperado de https://gestion.pensemos.com/que-esun-mapa-estrategico-en-el-balanced-scorecard-y-como-se -hace

Takeuchi, H. (2012). Grupo Fast Retailing (caso 713-S21). Recuperado del sitio de internet de Universidad Harvard, Escuela de Negocios:

https://www.harvard.edu/

Vega Polanco, M. (28 de Agosto 2017). Política fiscal del Perú es una de las mejores de América Latina. El Peruano. Recuperado de https://www.elperuano.pe/noticiabm-politica-fiscal-del-peru-es-una-las-mejores-america-latina-58851.aspx 